\title{
Effect of Methylcellulose on Rectal and Colonic Pressures in Treatment of Diverticular Disease
}

\author{
JOHN HODGSON
}

British Medical fournal, 1972, 3, 729-731

\section{Summary}

Six patients with diverticular disorder confirmed by barium-enema examination were given a six-month course of methylcellulose (Celevac) tablets; their rectal and rectosigmoid colonic pressures were measured before and afterwards. Open-tipped, fluid-filled, narrowbore polyethylene tubes were used for pressure measurements and care was taken to site the tubes similarly in all patients before and after treatment. After methylcellulose treatment the mean rectosigmoid pressures had fallen to the same range as the mean rectal pressures, a highly significant reduction. Methylcellulose significantly reduces rectosigmoid pressures in diverticular disease.

\section{Introduction}

Painter, Almeida, and Colebourne (1972) have shown that patients with diverticular disorder improve symptomatically when treated with unprocessed bran. Hodgson (1972) found that intracolonic pressures in rabbits increase on low-residue diets. A trial was designed to test the effect on rectal and colonic pressures in diverticular disease when methylcellulose (Celevac) tablets are used for high-residue treatment. Methylcellulose was chosen because it has been used for many years in the management of colostomies (Clayton Jones, 1956) and is known to be non-toxic, passing through the digestive tract largely unaltered (Machle, Heyroth, and Witherup, 1944).

\section{Patients and Methods}

Four women and two men (mean age 69.5 years) with diverticular disease confirmed by barium-enema examination were referred to the rectal clinic at Fulham Hospital for treatment. They had continued normal feeding except lunch, which was provided as part of the experiment.

History-taking was standardized by means of a form (Fig. 1), and after clinical examination and sigmoidoscopy two fine,

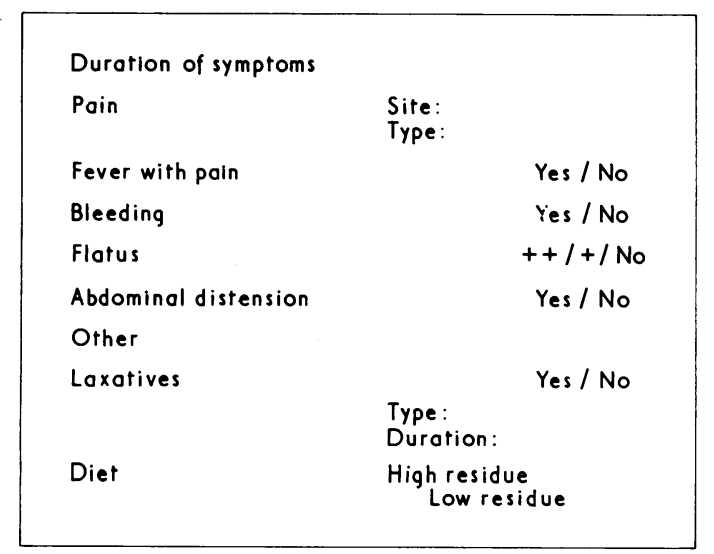

FIG. 1-Standard form for investigation of diverticular disease.

Professorial Surgical Unit, St. George's Hospital, London S.W.17 JOHN HODGSON, F.R.c.s., Lecturer in Surgery

open-tipped polyethylene tubes of $1.2 \mathrm{~mm}$ internal diameter were placed as shown in Fig. 2 with the proximal tube at or beyond the rectosigmoid junction and the tip of the other tube situated $10 \mathrm{~cm}$ distal in the rectum (Ritchie, Ardran, and Truelove, 1962).

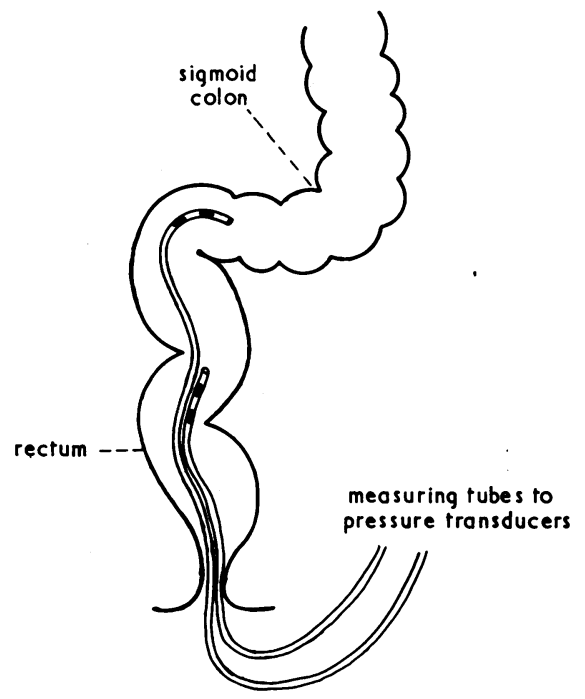

FIG. 2-Positions of tubes in colon and rectum.

After 20 to $\mathbf{3 0}$ minutes resting pressures were recorded for $\mathbf{3 0}$ minutes, a meal (Holdstock and Misiewicz, 1970) was given during which recording continued, and, finally, postprandial pressures were recorded for a further $\mathbf{3 0}$ minutes.

Each patient was given two tablets of methylcellulose daily which could be increased if there was no improvement. The dose was continued, with two-monthly checks, to the end of the six-month trial, after which pressure measurements were repeated.

\section{Results}

\section{ANALYSIS OF RECORDINGS}

Most of the waves described by Chaudhury and Truelove (1961a) in normal people were type I or "fast," with a gentle rise and fall of pressure. Painter and Truelove (1964) agreed with them that it was difficult to categorize waves but showed that most waves in both normal subjects and patients with diverticulosis were fast. Wangel and Deller (1965) also found that most waves were fast but thought that they were associated with the irritable colon syndrome. Connell (1961) studied normal subjects and patients with asymptomatic duodenal ulcer and showed that most fast waves occurred in the rectum in both groups. Parks (1970) recorded that most fast waves also occurred in the rectum, and particularly in patients who had had their sigmoid colon resected for diverticular disease. In the present study of patients with diverticular disorder most waves in the colon and rectum lasted less than 10 seconds and their amplitude was less than $10 \mathrm{~mm} \mathrm{Hg}$. These "fast" waves had a sharp rise and then an equally sharp fall in pressure (Fig. 3). After the course of methylcellulose the numbers of fast waves were reduced but were still predominant.

The next most common group in this study corresponded 
to the type II waves described by Texter and Hightower (1970) in normal subjects-that is, monophasic waves 10 to $50 \mathrm{~mm} \mathrm{Hg}$ in amplitude and 10 to 60 secs in duration. Adler, Atkinson, and Ivy (1941), Spriggs, Code, Bargen, Curtiss, and Hightower (1951), Connell (1961), Wangel and Deller (1965), and Parks (1970) thought that this was the predominant type of wave in the lower bowel. In the present patients with diverticular disease there was little difference in appearance between these waves and the large waves described as type IV waves in

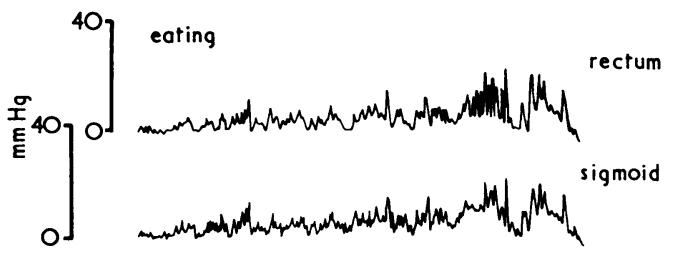

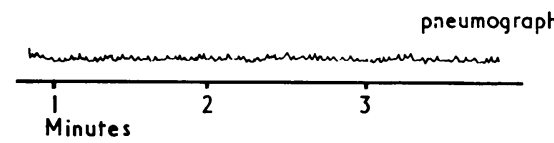
FIG. 3-Tracings in man aged 70 before methylcellulose treatment. Most
waves were fast but sigmoid lead showed two complex waves at end of waves were fast but sigmoid lead showed two
tracing; rectal lead showed one complex wave.

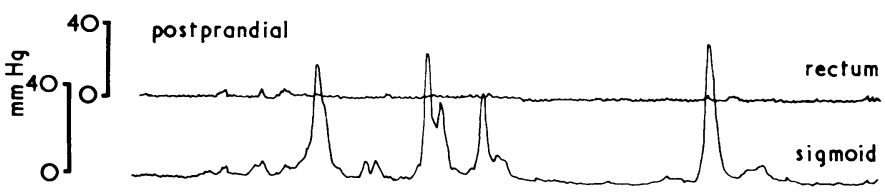

neumograph

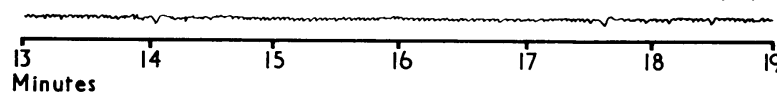

FIG. 4-Tracings in woman aged 57 before methylcellulose treatment. Four large simple waves are recorded on sigmoid lead.

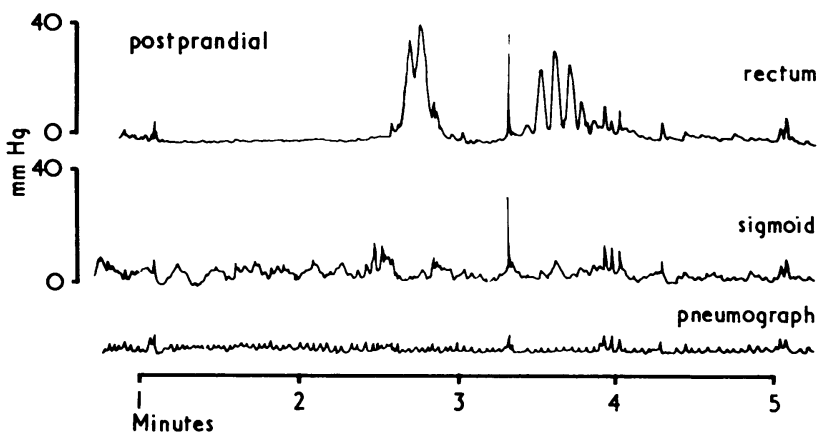

FIG. 5-Same patient as in Fig. 3; tracings before methylcellulose treatment. Complex wave appeared after cough on rectal lead.

ulcerative colitis (Davidson, Sleisenger, Almy, and Levine 1956)-these were monophasic waves two to three times higher than the type II waves and had a duration of two to five minutes -except that they did not achieve the same duration (Fig. 4). It is proposed that the term "simple" should cover types II and IV waves, since exact division into various classes of wave is difficult to achieve meaningfully (Chaudhury and Truelove, 1961b).

The third type of wave was the "complex," which was characterized by a slow rise and fall of baseline pressure on which fast and simple waves were superimposed (Fig. 5). Texter and Hightower (1970) defined type III waves as having a duration of 1 to 15 minutes with a rise of the baseline pressure of from 3 to $10 \mathrm{~mm} \mathrm{Hg}$. The maximum width and height of the complex waves were chosen for the current study, and since the areas excluded and included by such measurements tended to cancel out this gave a fair indication of the pressure involved.

\section{QUANTITATIVE ANALYSIS}

There were six periods available for analysis on each patient before treatment and these could be compared with six periods available for analysis on each patient after methylcellulose. Thus a total of $\mathbf{7 2}$ periods were available for comparison.

All pressure recordings were closely inspected and all waves which were due to movement, respiration, or talking or coughing were eliminated. Further, all waves below a minimum width of 2.5 seconds and height of $3 \mathrm{~mm} \mathrm{Hg}$ were eliminated to reduce error due to interference. The recording time and number of waves in this time were noted. A computer program was designed to convert these measurements to any stated standard time, to standardize pressures, and to exclude any waves below the previously stated limit. Several variables could therefore be calculated.

The colonic motility index (Chaudhury and Truelove, 1961a) is a quantitative expression of all variables including total pressure, duration of activity, and number of waves, thus representing all types of activity. Accordingly the colonic motility index was calculated as the sum of the products of the width and height of each wave, corrected to a standard time, summarized as follows:

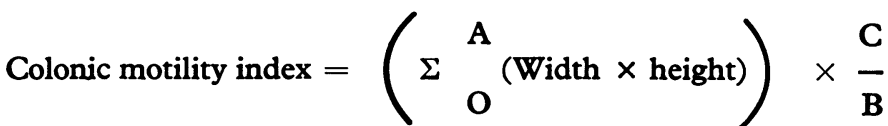

where $A$ was the number of waves, $C$ was the standard time (30 minutes), and B was the observed time. After six months on methylcellulose all patients showed a highly significant fall in proximal colonic motility, but the distal readings were unchanged. The mean values are given in the Table.

Mean Proximal and Distal Colonic Motility Index (see Text) before and after Methylcellulose Treatment

\begin{tabular}{|c|c|c|c|c|c|c|c|}
\hline & & \multicolumn{3}{|c|}{$\begin{array}{l}\text { Proximal Colonic } \\
\text { Motility Index }\end{array}$} & \multicolumn{3}{|c|}{$\begin{array}{l}\text { Distal Colonic } \\
\text { Motility Index }\end{array}$} \\
\hline & & Before & After & $\mathbf{P}$ & Before & After & $\mathbf{P}$ \\
\hline $\begin{array}{l}\text { Resting } \\
\text { Feeding } \\
\text { Post prandial }\end{array}$ & $\begin{array}{l}. . \\
\because\end{array}$ & $\begin{array}{r}7,577 \\
13,592 \\
8,237\end{array}$ & $\begin{array}{l}1,236 \\
2,645 \\
1,761\end{array}$ & $\begin{array}{l}<0.025 \\
<0.01 \\
<0.05\end{array}$ & $\begin{array}{r}560 \\
2,999 \\
2,358\end{array}$ & $\begin{array}{r}719 \\
2,970 \\
1,021\end{array}$ & $\begin{array}{l}<0.45 \\
<0.2\end{array}$ \\
\hline
\end{tabular}

\section{CLINICAL FINDINGS}

All patients became symptom-free after treatment. Before methylcellulose residual faeces were always present in the rectum in all patients, even when they thought they were clear. Gentle removal was necessary before placement of the pressuremeasuring tubes, avoiding excessive insufflation. Spasm was present at the rectosigmoid junction in four patients. Sigmoidoscopy after six months on methylcellulose showed an empty rectum in each case, and spasm at the rectosigmoid was reduced in degree although still present in three patients.

\section{Discussion}

Painter (1969) and Burkitt (1969) suggested that the low-residue diet of western civilization is the cause of diverticular disease. Rectosigmoid pressures were found to be raised in diverticular disorder (Painter, 1962; Arfwidsson, 1964; Parks and Connell, 1969; Parks, 1970) and were shown to be significantly greater than in the rectum (Parks and Connell, 1969; Parks, 1970). Reduction of these pressures by provision of high-residue 
intake to patients with diverticular disorder would add much weight to the theory that the cause of the disease is dietary.

Spriggs et al. (1951), Connell (1961), Arfwidsson (1964), Wangel and Deller (1965), Misiewicz, Connell, and Pontes (1966), Parks and Connell (1969), Texter and Hightower (1970), and Parks (1970) found that activity in control subjects in the sigmoid, rectosigmoid, and rectum was increased by eating, but to a less extent than in diverticular disease (Arfwidsson, 1964; Parks and Connell, 1969; Parks, 1970).

The pressure studies recorded here confirm these findings and show that after a six-month course of methylcellulose rectosigmoid activity does fall and to the same range as rectal activity, which remains unchanged. Parks (1970) noted that rectal activity increased after excision of the sigmoid for diverticular disease and suggested that this operative treatment threw an added load on the continence mechanism of the rectum, with a great increase in fast-wave activity. Medical treatment with methylcellulose has not had this disadvantage.

Methylcellulose tablets, which expand to 25 times their original size after ingestion and were more acceptable to the patients than granules, were used to ensure that the patients under investigation received the necessary high residue. In addition to the pressure changes discussed all patients became asymptomatic. The improved sigmoidoscopic appearance could only be interpreted as evidence that methylcellulose overcame constipation without damaging the myenteric plexus by helping in the formation of large firm stools which could be passed easily per rectum without straining. It was therefore safe to maintain patients on methylcellulose as these patients with diverticular disease have a persistent tendency to eat low-residue foods.

This work suggests that the muscular abnormality of diverticular disease (Morson, 1963; Williams, 1965; Hughes, 1969) is acquired (Painter, 1969) and is reversible.
This work was carried out on a Charing Cross Governors' Clinical Research Fellowship and is part of the work for my M.S. thesis (London University). I wish to thank Professor Harding Rains for referring patients for this study and Mrs. J. Pheasant and Miss K. Marsh for their help in pressure recordings and wave measurement.

\section{References}

Adler, H. F., Atkinson, A. J., and Ivy, A. C. (1941). American fournal of Digestive Diseases, 8, 197.

Arfwidsson, S. (1964). Acta Chirurgica Scandinavica, Suppl. No. 342

Arfwidsson, S. (1964). Acta Chirurgica
Burkitt, D. P. (1969). Lancet, 2, 1229 .

Burkitt, D. P. (1969). Lancet, 2, 1229.

Chaudhury, N. A., and Truelove, S. C. (1961a). Gastrcenterology, 40, 1. (1961b). American fournal of Medicine, $31,86$.

Clayton Jones, E. (1956). Medical Press, 235, 551.

Connell, A. M. (1961). Gut, 2, 175.

Davidson, M., Sleisenger, M. H., Almy, T. P., and Levine, S. Z. (1956). fournal of Pediatrics, $17,807$.

Hodgson, J. (1972). British fournal of Surgery, 59, 315.

Holdstock, D. J., and Misiewicz, J. J. (1970). Gut, 11, 100.

Hughes, L. E. (1969). Gut, 10, 336.

Machle, W., Heyroth, F. F., and Witherup, S. (1944). Journal of Biological Chemistry, 153, 551

Misiewicz, J. J., Connell, A. M., and Pontes, F. A. (1966). Gut, 7, 468.

Misiewicz, J. C. (1963). British fournal of Radiology, 36, 385.

Mainter, N. S. (1962). M.S. thesis London University.

Painter, N. S. (1962). M.S. thesis Lo

Painter, N. S. (1969). Lancet, 2, 586. 1964$)$. Gut, 5, 201, 365.

Painter, N. S., Almeida, A. Z., and Colebourne, K. W. (1972). British Medical Yournal, 2, 137

Parks, T. G. (1970). Gut, 11, 121

Parks, T. G., and Connell, A. M. (1969). Gut, 10, 534.

Ritchie, J. A., Ardran, G. M., and Truelove, S. C. (1962). Gastroenterology, 43, 642 .

Spriggs, E. A., Code, C. F., Bargen, J. A., Curtiss, R. K., and Hightower, N. C. (1951). Gastroenterology, 19, 480

Texter, E. C., jun., and Hightower, N. C., jun. (1970). Rendiconti Istituto Superiore di Sanita, 2, 47.

Wangel, A. G., and Deller, D. J. (1965). Gastroenterology, 48, 69.

Williams, I. (1965). British fournal of Radiology, 38, 437.

\title{
Relation between Serum Cholesterol and Triglyceride Concentration and Haemoglobin Values in Non-anaemic Healthy Persons
}

\author{
L. E. BÖTTIGER, L. A. CARLSON
}

British Medical fournal, 1972, 3, 731-733

\section{Introduction}

\section{Summary}

In a study of 2,458 healthy non-anaemic subjects a positive correlation was found between haemoglobin levels and serum cholesterol and triglyceride levels. This may be due to simple changes in plasma volume, which may increase when the haemoglobin concentration decreases. Such an association between plasma lipid levels and haemoglobin values might be of importance in the aetiology of coronary heart disease, as a high haemoglobin value is known to be a "risk factor" in myocardial infarction.

\footnotetext{
Department of Internal Medicine, Karolinska Hospital, Stockholm, Sweden

L. E. BÖTTIGER, M.D., Professor of Medicine

Department of Geriatrics, Uppsala University, Uppsala, Sweden L. A. CARLSON, M.D., Professor and Head of Department
}

Although Erben in 1902 reported low cholesterol levels in chlorosis, the possible relation between anaemia and hypolipidaemia did not attract much attention until the late 1960 s, when Rifkind and Gale (1967) reported on a small study of anaemic patients who also had low serum cholesterol and phospholipid levels. Ultracentrifuge analysis showed a proportionate decrease of cholesterol and phospholipids in all three main plasma lipoprotein fractions. Elwood et al. (1970), in a community-based study, found a statistically significant association between serum cholesterol and haemoglobin level. They found a mean difference of about $30 \mathrm{mg}$ of cholesterol per $100 \mathrm{ml}$ of blood between women with haemoglobin levels above and below 10.5 $\mathrm{g} / 100 \mathrm{ml}$.

Studies on the possible association between haemoglobin and serum cholesterol and haemoglobin and serum triglycerides in non-anaemic subjects have not been done previously. We have analysed fasting serum lipids (cholesterol and triglycerides) in about 6,500 persons in whom haemoglobin and erythrocyte sedimentation rate were also determined and have found a positive correlation between haemoglobin concentration and the two plasma lipids in both women and men, throughout the whole range of normal haemoglobin values. 